\title{
Social dynamics in judgment and performance in academic settings
}

\author{
Céline Buchs
}

Armand Chatard

University of Geneva, Switzerland

Olivier Desrichard

University of Savoy, France

Gabriel Mugny

University of Geneva, Switzerland

In recent years there has been an increasing recognition of the pervasive influence of the social context on students' judgment and performance (e.g., Monteil \& Huguet, 1999; Croizet \& Leyens, 2003; Mugny \& Guimond, 2007). Students' evaluations and opinions are constantly being pushed and pulled by social influence dynamics. Their attitudes and performances shift in response to those around them, to the expectation of others, to the composition of the group in which they work, to the presentation of academic tasks, or to the salience of cultural stereotypes in academic settings. The aim of this issue was to gather work addressing the impact of social contexts on educational outcomes. The articles included in this issue investigate the social dynamics involved in students' learning, performances and motivations, in conjunction with social judgments and, in particular, social stereotypes. They concern various educational settings, i.e., school, higher education, or computer mediated communication environments. The social dynamics involved in students' performances and learning are investigated using various approaches that are combined in some papers. The first approach addresses the impact of the social context by experimentally manipulating task presentation (as diagnostic or not of intellectual abilities, or as gender oriented), group composition (students' numerical status or gender composition) or resource interdependence (by providing group members with identical or complementary information). A second slant with regards to this topic investigates the effects of group or category membership, differentiating individuals on the basis of social characteristics like gender, socioeconomic status or ethnic origin. Another way to consider the social dimension in educational outcomes is to study the impact of the actual partner's behaviours by varying the partner's communication style (quality of informational input, forms of tutor help or teacher's authority style) or evaluating the influence parents' and teachers' judgments have on the students' motivation to learn, achievement goals or self-conception. The papers in this issue illustrate these different approaches. 
To begin with, three papers concern symmetrical dyadic cooperative learning at university. The two first papers propose that the way resource or knowledge interdependence is structured influences learning. Molinari, Sangin, Dillenbourg, and Nüssli test the hypothesis that mutual knowledge model accuracy (the difference between estimated knowledge level and actual learning score) will mediate the effects of knowledge interdependence on computer supported collaborative learning. Their results indicate that knowledge interdependence affects mutual knowledge modelling, but not learning. Students build a more accurate model of their partner's knowledge when they share identical information. Moreover, they assess their partner's outcome knowledge more accurately than their own knowledge when they work on similar information, whereas, the reverse is found when they work on complementary information. However, no link is found between the accuracy mutual knowledge modelling and learning.

Buchs and Butera argue that the partner's competence does moderate the effect of resource interdependence on learning. The partner's competence is shown to be beneficial when students work on complementary information, whereas, it is detrimental when they work on identical information. These contrasted dynamics are underlined by two different mechanisms that take place during peer learning. Informational dependence is critical when students work on complementary information, and positive student interactions are favourable for learning provided that the quality of informational input is high. When students work on identical information, a competence threat is salient despite cooperative instructions, and the partner's competence has a deleterious effect on learning.

Michinov, Michinov, and Huguet examine the effects of gender role and task content on performance in learning dyads. They suggest that communal behavior would favor collective learning, and that female dyads activate more communal attributes than male dyads especially in a congruent feminine task. Results indicate that task content moderates the effect of group composition on performance: male dyads perform more poorly on a masculine task than female dyads. Moreover, male dyads perform more poorly on a masculine task than on feminine task, whereas female dyads perform at the same level on a feminine task and a masculine task. The authors propose that difference in communication, coordination and collaboration behaviors within groups (transactive memory system) will mediate the interaction between gender composition and task content. However, the transactive memory system only mediates the effect of group gender on learning.

Two other papers investigate students' learning in an asymmetric relationship at university. Olry-Louis shows that in order for tutoring to be beneficial in a reasoning task, supportive feedback is not enough. Tutoring is beneficial and is perceived in that way if the tutor provides feedback regarding the content. Moreover, novices judge tutors' aid more positively when the tutors use questions in comparison to when they use directives to assist the novice. Nevertheless these two forms of tutoring with a focus on content have the same positive effect on novice learning.

Quiamzade, Mugny, and Falomir investigate social influence processes at work at the university. They measure the influence of a lecturer on information appropriation as a function of the epistemic authority's styles. Students were informed that academic success ( $v s$. failure) was higher among students who acknowledge the influence of their teachers. They then were exposed to information from a lecturer that contradicted one of their beliefs. This information was framed in an authoritarian or a democratic way. Their results demonstrate that the acknowledgement of their epistemic dependence has a different impact on information appropriation according to the authority's style: the higher the acknowledgement, the stronger the appropriation under the democratic style, but the weaker the appropriation under the authoritarian style.

The previous papers focused on the way learning situations are structured and the way in which partners' behaviours are important for performance outcomes. Some of the following papers illustrate that performances also depend on category membership and group stereotypes. Viallon and Martinot indicate that performance in educational settings depends on students' numerical status in the social context. They focus their attention on a well-established finding 
that being the only representative of one's gender in a performance situation (solo status) is more detrimental to women's than to men's performance. They argue that the context in which a task is performed can moderate this effect. Findings illustrate that when the "leader" stereotype is salient in a performance situation, a solo female performs worse than in a situation in which a gender stereotype whereby women outperform men on tasks is rendered salient by an intergroup comparison. In a second study, the opposite effect is predicted and found for solo men: they were less successful in the intersex comparison context than in a group work context in which comparison was not rendered salient.

Désert, Préaux, and Jund set out to show that even very young children can be victims of stereotype threat (i.e., the fear of confirming a negative in-group stereotype). To this end, eight- and nine-years olds filled in Raven's progressive matrices in evaluative or nonevaluative conditions. In the first condition, the instructions recommended by the test designers were used. In the second condition, the test was presented as a game. Consistent with the stereotype threat literature, low socioeconomic status children perform worse under evaluative pressure, whereas, high socioeconomic status children's performance is unaffected by the evaluative $v s$. non-evaluative context.

Chateignier, Dutrévis, Nugier, and Chekroun examine stereotype threat from the viewpoint of implicit cognition. In a first study, these authors show that native French students express an automatic stereotype of French-Arab students' alleged inferior intellectual ability, by using an Implicit Association Test. Consistent with this finding, in a second study they document a stereotype threat effect among French-Arab students on a verbal task. When the task is presented as indicative of intelligence, French-Arab students perform worse than native French students. However, this difference disappears when the task is presented as being nondiagnostic of intelligence.

The mental representations of a title or an occupation can depend on the grammatical form (masculine generic vs. gender-neutral generic) used to present it. Gygax, Gabriel, Sarrasin, Oakhill, and Garnham argue that the grammatical generic rule of the masculine is not as readily applied as it is learned. On the basis of a literature review and their own recent work, these authors show that the representation of gender when reading role names depends on an interaction between stereotypical and grammatical information. In particular, even though individuals are aware of and understand the generic masculine rule, the generic masculine form is associated with men only in gender marked languages.

The last two papers in this special issue focus on students' self-perception and motivation to learn. Nurra and Pansu examine how social judgments of significant others (parents, teachers, peers) affect the judgments children have of themselves on academic, but also non academic, dimensions. They study the impact of significant others' judgments (actual appraisals) on self-perception in children between the ages of 8-9. In line with Cooley's assumption that this impact should be mediated by the perception children have of others' actual appraisal (reflected appraisal), parents' actual appraisal effect on self-perception appears to be partially mediated by reflected appraisal for academic competence, behavioral conduct, social acceptance and physical ability. For teachers, it was the case specifically for academic competence and behavioral conduct, the two judgmental dimensions most relevant in the school context.

Finally, Régner, Loose, and Dumas investigate whether students' perceptions of parental and teacher academic support and academic monitoring influence students' achievement goals. Results indicate that students' perceptions of parental academic support were positively related to mastery goals whilst they were unrelated to performance goals. Moreover, perceived academic monitoring was associated with performance goals, although the findings revealed an equal contribution of perceived parental and teacher involvement. This new insight about the antecedents of students' achievement goals emphasizes how important the role of parental and teacher academic socialization is.

Collectively, the papers included in this special issue provide converging evidence that the social context plays a major role in shaping students' judgement and performance in academic settings. The good news is that teachers, educators, and professionals can contribute 
to changing students' attitudes, behaviours and learning by modifying the social contexts. Some modifications would necessitate the adoption of new policies, which are beyond the control of teachers. However, social and educational researchers can provide some practical recommendations that may help.

The editors are indebted to several social scientists, who diligently acted as reviewers on the papers considered for this special issue, namely Ann Beaton, Elodie Baerlocher, Pieter J. Beers, Virginie Bonnot, Rebecca S. Bigler, Julien Bois, Pascal Bressoux, Aïna Chalabaev, Jean-Claude Croizet, Fabrice Gabarrot, Marie-Anne Hugon, Teresa I. Jiménez, Martine Lagacé, Katia Lehraus, Richard Moreland, Angela O'Donnell, Gabrielle Poeschl, Roxanne de la Sablonnière, Edith Sales-Wuillemin, Leila Selimbegović, and Christine Sorsana. Their invaluable help was greatly appreciated.

\section{References}

Croizet, J.-C., \& Leyens, J.-P. (Eds.). (2003). Mauvaises réputations. Réalités et enjeux de la stigmatisation sociale. Paris: Armand Colin.

Monteil, J.-M., \& Huguet, P. (1999). Social context and cognitive performance. Towards a social psychology of cognition. Hove: Psychology Press.

Mugny, G., \& Guimond, S. (Eds.). (2007). Social psychological analyses of educational dynamics. European Journal of Psychology of Education, 22(3), 221-398. 